\title{
Análise da Intersetorialidade entre as Políticas Públicas para o Desenvolvimento Urbano Sustentável no Brasil
}

\section{Analysis of the Intersectoriality between Public Policies for Sustainable Urban Development in Brazil}

\author{
Santos, Laini ${ }^{1}$ \\ 1 Universidade Federal de Santa Catarina (UFSC), Rua Elaine Cristina, n 514 \\ bairro Jardim Eldorado, Palhoça, Santa Catarina - Brasil, e-mail: \\ laine.souza20@gmail.com
}

\begin{abstract}
RESUMO
O desenvolvimento de políticas públicas no Brasil sempre esteve alinhado ao papel do estado, com maior incidência após a década de 2000, quando houve um esforço de realinhamento de sua função diretiva após um período de hegemonia do ideário neoliberal de minimização, que marcou o governo federal desde as décadas passadas. Essas políticas estão presentes em todas as áreas de desenvolvimento, contudo a desarticulação delas é, de longe, uma dos maiores problemas no que tange a efetivação. Este trabalho tem como objetivo analisar a intersetorialidade entre as políticas públicas brasileiras para 0 desenvolvimento sustentável das cidades, bem como a práxis dos agentes que contribuem para esse processo. É resultado de um trabalho final de Pós-Graduação. Para realizar o estudo, utilizou-se a abordagem de pesquisa qualitativa, na qual foram trabalhadas as 21 políticas públicas que envolvem o espaço urbano brasileiro. Como resultado, percebeu-se das 21 políticas públicas analisadas apenas 2 apresentam intersetorialidade em suas diretrizes, e todas exibem deficiências em sua efetivação, reforçando que a abundância dessas ferramentas não concretiza seus objetivos.
\end{abstract}

Palavras-chave: Desenvolvimento sustentável, Políticas públicas, Espaço urbano.

\begin{abstract}
The development of public policies in Brazil has always been in line with the role of the state, with greater incidence after the decade of 2000, when there was a realignment effort of its directive function after a period of hegemony of the neoliberal ideology of minimization, that marked the federal government since the past decades. These policies are present in all areas of the development; however, their disarticulation is by far one of the biggest problems in terms of effectiveness. This work aims to analyze the intersectoriality between Brazilian public policies for the sustainable development of cities, as well as the praxis of the agents that contribute to this process. It is the result of a final postgraduate work. To carry out the study, the qualitative research approach was used, in which the 21 public policies that involve the Brazilian urban space were worked. As a result, one can perceive the 21 public policies analyzed, only 2
\end{abstract}

1 SANTOS, Laini. Análise da Intersetorialidade entre as Políticas Públicas para o Desenvolvimento Urbano Sustentável no Brasil. In: II SIMPÓSIO NACIONAL DE GESTÃO E ENGENHARIA URBANA: SINGEURB, 2019, São Paulo. Anais... Porto Alegre: ANTAC, 2019. 
present intersectoriality in their guidelines, and all show deficiencies in their effectiveness, reinforcing that the abundance of these tools does not materialize their objectives.

Keywords: Sustainable development, Public policies, Urban space.

\section{INTRODUÇÃO}

As discussões sobre o desenvolvimento das cidades elevaram sua importância em todo o mundo nos últimos anos, tanto para as políticas de Estado como para o meio acadêmico e conscientização da sociedade civil. As justificativas, geralmente, partem do rápido processo de urbanização decorrente das novidades advindas do cenário tecnológico introduzido pela Revolução Industrial e subsequente a prosperidade do Pós Segunda Guerra Mundial que gerou grandes efeitos no modo de vida da população, sobretudo na esfera ambiental.

O contexto que envolvia esse paradigma passou a questionar a relação homem/natureza por meio do padrão econômico baseado na exploração dos recursos naturais sem nenhuma precaução. No entanto, foi somente a partir da década de 1970 que se instaurou um novo pensamento, com intuito de aliar as questões sociais, econômicas e ambientais ao progresso equilibrado das futuras gerações, isto é, estabelecer o desenvolvimento sustentável. No Brasil, o contexto do desenvolvimento Sustentável se subdivide em mais de trinta e cinto Políticas, sua maioria foram extraídas da Agenda 21 Global e compatibilizadas com a realidade do país, além disso, soma-se o Estatuto da Cidade e da Metrópole. Esse trabalho tem como objetivo analisar a intersetorialidade entre essas políticas públicas, bem como a práxis dos agentes que contribuem para esse processo.

\section{POLÍTICAS PÚBLICAS PARA O DESENVOLVIMENTO URBANO SUSTENTÁVEL}

O contexto das Políticas Públicas sempre caminhou em torno do Estado. Os principais indícios concretos nasceram na Europa, no início do século XX, embora algumas ações dos anos anteriores remetam a ideia central do termo. Segundo Souza (2006) o contexto daquele momento se concentrava mais na análise sobre o Estado e suas instituições, do que na produção dos governos. Posteriormente, no ano de 1930, nos Estados Unidos, surgiram alguns estudiosos (Harrold Lasswell, Herbert Simon, Charles Lindblom e David Easton), considerados atualmente "pais" das Políticas Públicas, que conforme Souza (2006), passaram a conciliar o conhecimento científico/acadêmico com a produção empírica dos governos, como forma de estabelecer o diálogo entre cientistas sociais, grupos de interesse e governo.

Esse entendimento estimulou a admissão do conceito como ferramenta das decisões do governo, e de acordo com Souza (2006) se expandiu para outras áreas da produção governamental, inclusive para a política social e ambiental. O desenvolvimento das políticas públicas referentes ao meio ambiente se deu com as perspectivas de crescimento das cidades, que segundo Lima e Kruger (2004) acentuou a necessidade da sociedade buscar formas de tornar o processo de desenvolvimento urbano sustentável, de modo a evitar ou minimizar as alterações climáticas decorrentes da urbanização, reduzir a polvição ambiental e garantir a preservação ou a construção de um ambiente urbano saudável para as gerações presentes e futuras. Esse discurso só passou a vigorar, segundo Scantimburgo (2011), com o surgimento do movimento ambientalista em meados do século XX, e dos diversos estudos realizados pela Organização das Nações Unidas (ONU) que apontavam já nas décadas de 1950/60 os impactos causados pelo homem na natureza.

O tema se propagou e incorporou os mais diversos discursos, dado que foram realizados eventos de grande magnitude, como por exemplo, a Primeira Conferência das Nações Unidas sobre o Meio Ambiente e o Homem (CNUMAH), em 1972, em Estocolmo, na Suécia. Esta conferência, conforme Scantimburgo (2011), abordou problemas relacionados ao crescimento demográfico, industrialização e expansão da urbanização, como também a proclamação da ONU do direito do ser humano viver num ambiente saudável e responsável por protegê-lo para as futuras gerações. 
No Brasil, o cenário relativo às Políticas Públicas, inicialmente, seguiu o processo histórico desenvolvimentista, conservador, centralizador e autoritário do Estado (BACELAR, 2003). Ao longo dos anos, o percurso foi adquirindo novos panoramas, mas só apresentou, de fato, mudanças significativas em 1988, com a Promulgação da Constituição Federal (CF), que inseriu a participação popular na elaboração das Políticas do país. Com isso, todas as áreas de desenvolvimento brasileiro passaram a trabalhar, através do cenário teórico, a partir de uma gestão mais participativa e democrática, sobretudo as que envolvem os âmbitos da saúde, social e urbano. Posteriormente, passou-se a questionar a forma de efetividade e articulação dessas Políticas, dado que se introduziu o conceito de Intersetorialidade.

Deste modo, a intersetorialidade passou a ser um dos requisitos para a implementação das políticas setoriais, visando sua efetividade por meio da articulação entre instituições governamentais e a sociedade civil (NASCIMENTO, 2010). Essa ferramenta tem sido fundamental para o desenvolvimento das Políticas Públicas brasileiras, pois contribui para a conexão entre saberes diferentes, unidos para um escopo maior com preocupação geral.

\section{METODOLOGIA}

Os recursos metodológicos utilizados ao longo desse estudo possuem abordagem Qualitativa, de Natureza Aplicada e conforme os seus objetivos, se classifica como exploratórios. Para executar o escopo principal do trabalho, selecionou-se as principais Políticas Públicas para o Desenvolvimento Urbano Sustentável no Brasil, a partir do estudo Políticas Públicas para Cidades Sustentáveis: Integração Intersetorial, Federativa e Territorial, proposto em 2016, pelo Governo Federal, através do Ministério da Ciência, Tecnologia e Inovação (MCTI), Ministério do Meio Ambiente (MMA) e o Instituto Brasileiro de Administração Municipal (IBAM). A escolha por esse caminho ocorreu devido à falta de uma base de dados de fácil acesso para coleta, que reúna todos os elementos sobre as Políticas Públicas realizadas pelo Governo Federal.

\section{ANÁLISE DOS RESULTADOS}

Conforme Brasil (2016), o espaço urbano brasileiro dispõe de mais de trinta e cinco Políticas (distribuídas em cinco eixos temáticos: Construções Sustentáveis, Mobilidade e Transporte Coletivo, Saneamento Ambiental, Sistema Sustentáveis de Energia, Uso e Ocupação do Solo), e outras fontes de grande importância, como o Estatuto da Cidade e o Estatuto da Metrópole. Todas essas Políticas passaram por um rastreamento dos possíveis alinhamentos de interesses comuns, entendidos como os objetivos e as diretrizes presentes nas leis e decretos que dialogam sobre o Desenvolvimento Sustentável das Cidades. Com isso, apenas vinte e uma dessas Políticas (dispostas no Quadro 1) compreendem em seu texto original algum requisito básico compatível com o Desenvolvimento Urbano Sustentável. 
Quadro 1 - Políticas Públicas relacionadas com o desenvolvimento urbano sustentável

\begin{tabular}{|c|c|c|l|}
\hline ANO & LEIS/DECRETOS & SIGLA & \multicolumn{1}{|c|}{ POLítICAS PÚBLICAS NACIONAIS } \\
\hline 1981 & Lei 6.938 & PNMA & Política Nacional do Meio Ambiente \\
\hline 1984 & Lei 7.232 & PNInf & Política Nacional de Informática \\
\hline 1997 & Lei 9.433 & PNRH & Política Nacional de Recursos Hídricos \\
\hline 1997 & Lei 9.478 & PEN & Política Energética Nacional \\
\hline 1999 & Lei 9.795 & PNEA & Política Nacional de Educação Ambiental \\
\hline 2001 & Lei 10.257 & EC & Estatuto da Cidade \\
\hline 2001 & Lei 10.295 & PNCURE & Política Nacional de Conservação e Uso Racional de Energia \\
\hline 2002 & Decreto 4.339 & PNBiod & Política Nacional de Biodiversidade \\
\hline 2004 & $\left({ }^{*}\right)$ & PNH & Política Nacional de Habitação \\
\hline 2007 & Decreto 6.047 & PNDR & Política Nacional de Desenvolvimento Regional \\
\hline 2007 & Lei 11.445 & PNSB & Política Nacional de Saneamento Básico \\
\hline 2008 & Lei 1.1771 & PNT & Política Nacional de Turismo \\
\hline 2009 & Lei 12.187 & PNMC & Política Nacional sobre Mudança do Clima \\
\hline 2010 & Lei 12.305 & PNRS & Política Nacional de Resíduos Sólidos \\
\hline 2011 & Lei 12.484 & PNMCB & $\begin{array}{l}\text { Política Nacional de Incentivo ao Manejo Sustentado e ao Cultivo } \\
\text { do Bambu }\end{array}$ \\
\hline 2012 & Lei 12.587 & PNMU & Política Nacional de Mobilidade Urbana \\
\hline 2012 & Lei 12.608 & PNPDEC & Política Nacional de Proteção e Defesa Civil \\
\hline 2013 & Lei 12.787 & PNIr & Política Nacional de Irrigação \\
\hline 2014 & Decreto 8.243 & PNPS & Política Nacional de Participação Social \\
\hline 2015 & Lei 13.089 & EM & Estatuto da Metrópole \\
\hline 2015 & Lei 13.153 & PNCDMS & $\begin{array}{l}\text { Política Nacional de Combate à Desertificação e Mitigação dos } \\
\text { Efeitos da Seca }\end{array}$ \\
\hline
\end{tabular}

Fonte: Brasil (2016)

Essas políticas apresentam imprecisões ou fragilidades em termos do seu enquadramento formal no arcabouço institucional do país, pois "em primeiro lugar, nem sempre se mantém uma estrutura na organização de políticas, tendo como consequência situações em que não se observa uma sequência esperada de política-plano-programa-projeto-ação" (BRASIL, 2016, p.83). Outro quesito importante é a fraca relação integradora das políticas com outros eixos. A figura 2 explana tal consenso, e foi realizada a partir do cruzamento entre as Política em estudo.

Figura 1 - Intersetorialidade entre as políticas públicas para o desenvolvimento urbano sustentável

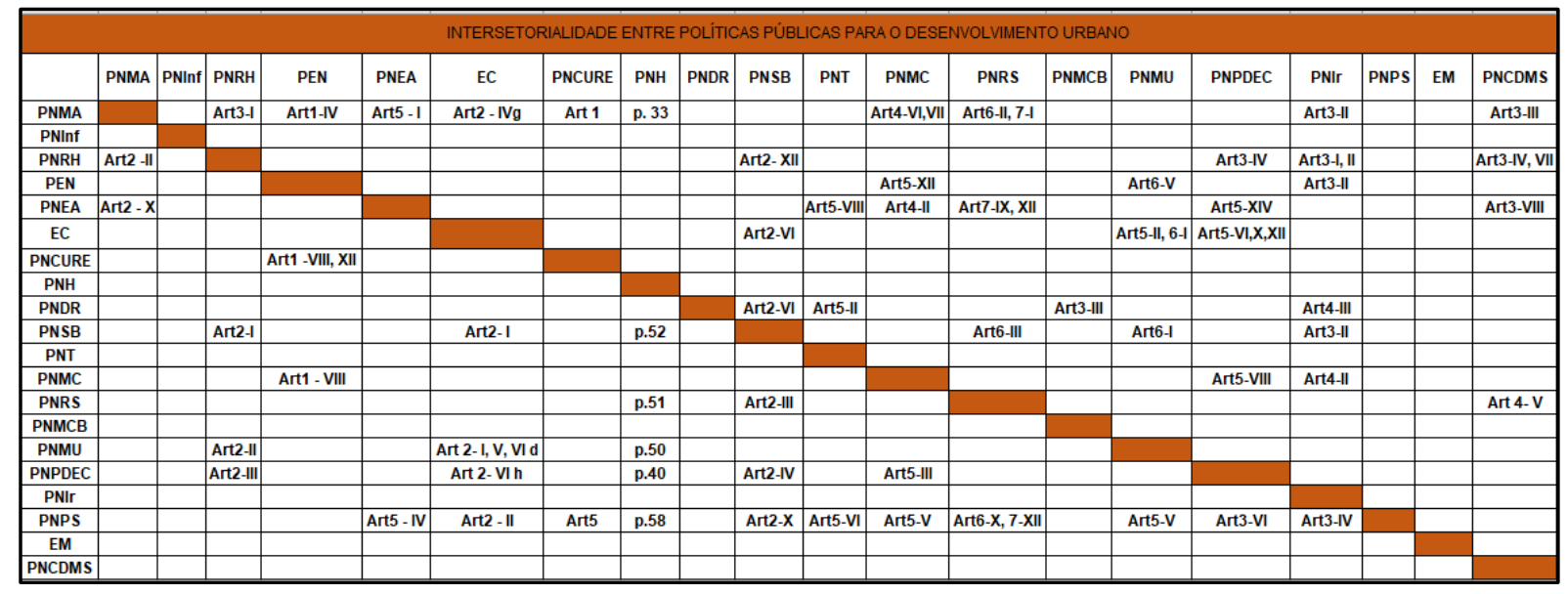

Fonte: A autora a partir dos dados de Brasil (2016)

Apenas a Política Nacional de Saneamento Básico (PNSB), Lei 11.445/2007, apresenta os maiores registros de conexões com as demais políticas nacionais. Já a Política Nacional de Proteção e Defesa Civil (PNPDEC), Lei 12.608/2012, Brasil (2016), aponta que é a segunda que 
mais se relaciona com as demais políticas, criando assim, um cenário favorável para o fortalecimento dos Objetivos do Desenvolvimento Sustentável (ODS). "Apesar disso, não foi identificada interação, pelo menos significativa, entre a Política Nacional de Saneamento Básico e a Política Nacional de Proteção e Defesa Civil" (BRASIL, 2016, p. 88).

As demais políticas apresentam poucas ou quase nenhuma intersecção entre seus eixos, o que torna a dinâmica extremamente preocupante. No que concerne a atuação de cada uma dessas Políticas, mesmo que de maneira particular, o panorama é também inconstante, e reforça que a abundância de políticas públicas não significa, necessariamente, efetiva coordenação, mas muitas vezes uma reação sintomática à necessidade de resposta ou de ocupação do cenário político (BRASIL, 2016).

\section{CONSIDERAÇÕES FINAIS}

Como já discutido, é de suma importância a Intersetorialidade entre essas políticas, pois permite a integração dos diversos eixos temáticos refletidos na estrutura administrativa de ministérios, secretarias, departamentos e outras unidades dos governos, e ainda focaliza nas horizontalidades da integração nas esferas dos governos nacional, estadual/distrital e municipal.

A partir dos dados apresentados nesse estudo pode-se dizer que as políticas públicas para o desenvolvimento urbano sustentável implicam na existência de dois quadros diferentes: o primeiro reflete as diversas políticas atuantes, mas todas com carências em seu corpo institucional e intersetorial, devido sua forma de realização; e o segundo, os agentes que produzem e concretizam as ações de cada política. É neste último que entra a ação da intersetorialidade, de maneira direta, e reforça como tal ferramenta pode ser decisiva para as iniciativas políticas. Percebeu-se ainda que o caminho para o desenvolvimento urbano sustentável, apesar de apresentar rotas importantes, segue labirintos infinitos, sendo que a sociedade civil, um dos principais agentes de execução das ações, não conhece nem o ponto de partida, transformando a situação em uma complexa passagem.

\section{REFERÊNCIAS}

BACELAR, T. As Políticas Públicas no Brasil: heranças, tendências e desafios. In: As Políticas

Públicas e Gestão Local: Programa Interdisciplinar de Capacitação de Conselhos

Municipais. Orlando Alves dos Santos Junior (et al.) (Org). Rio de Janeiro: Fase, 2003.

BRASIL. MINISTÉRIO DA CIÊNCIA, TECNOLOGIA E INOVAÇÃO. Políticas públicas para cidades sustentáveis: integração intersetorial, federativa e territorial. Rio de Janeiro: IBAM, MCTI, 2016.

LIMA, P. R.; KRÜGER, E. Políticas públicas e desenvolvimento urbano sustentável.

Desenvolvimento e Meio ambiente, Curitiba - PR, v.9, p. 9-21, jan./jun. 2004.

NASCIMENTO, S. Reflexões sobre a intersetorialidade entre as políticas públicas. Serv. Soc. Soc., São Paulo, n. 101, p. 95-120, jan./mar. 2010.

SCANTIMBURGO, A. L. Políticas Públicas e Desenvolvimento Sustentável: os limites impostos pelo capitalismo no gerenciamento e preservação dos recursos hídricos no Brasil. Aurora, ano V, número 7, jan, 2011.

SOUZA, C. Políticas Públicas: uma revisão da literatura. Sociologias, Porto Alegre, ano $8, n^{\circ} 16$, p. 20-45, jul/dez, 2006. 